\title{
Differential Effectiveness of Salicylate-Dependent and Jasmonate/Ethylene-Dependent Induced Resistance in Arabidopsis
}

\author{
Jurriaan Ton, Johan A. Van Pelt, L. C. Van Loon, and Corné M. J. Pieterse \\ Graduate School Experimental Plant Sciences, Section Phytopathology, Faculty of Biology, Utrecht University, \\ P.O. Box 800.84, 3508 TB Utrecht, The Netherlands
}

Submitted 2 July 2001. Accepted 21 September 2001.

Salicylic acid (SA), jasmonic acid (JA), and ethylene (ET) are each involved in the regulation of basal resistance against different pathogens. These three signals play important roles in induced resistance as well. SA is a key regulator of pathogen-induced systemic acquired resistance (SAR), whereas JA and ET are required for rhizobacteriamediated induced systemic resistance (ISR). Both types of induced resistance are effective against a broad spectrum of pathogens. In this study, we compared the spectrum of effectiveness of SAR and ISR using an oomycete, a fungal, a bacterial, and a viral pathogen. In noninduced Arabidopsis plants, these pathogens are primarily resisted through either SA-dependent basal resistance (Peronospora parasitica and Turnip crinkle virus [TCV]), JA/ET-dependent basal resistance responses (Alternaria brassicicola), or a combination of SA-, JA-, and ET-dependent defenses (Xanthomonas campestris pv. armoraciae). Activation of ISR resulted in a significant level of protection against $A$. brassicicola, whereas SAR was ineffective against this pathogen. Conversely, activation of SAR resulted in a high level of protection against $P$. parasitica and TCV, whereas ISR conferred only weak and no protection against $P$. parasitica and TCV, respectively. Induction of SAR and ISR was equally effective against $X$. campestris pv. armoraciae. These results indicate that SAR is effective against pathogens that in noninduced plants are resisted through SAdependent defenses, whereas ISR is effective against pathogens that in noninduced plants are resisted through JA/ETdependent defenses. This suggests that SAR and ISR constitute a reinforcement of extant SA- or JA/ET-dependent basal defense responses, respectively.

Additional keywords: disease resistance, Pseudomonas fluorescens.

Plants require a broad range of defense mechanisms to effectively combat invasions by microorganisms. These mechanisms include preexisting physical and chemical barriers, as well as inducible defense responses that become activated after pathogen infection, such as synthesis of phytoalexins, enhanced strengthening of cell walls, and the production of antifungal proteins (Jackson and Taylor 1996). The plant hormones

Corresponding author: Corné M. J. Pieterse; Telephone: +31 30 2536887; Fax: +31 30 2518366; E-mail: C.M.J.Pieterse@ bio.uu.nl

Current address of J. Ton: Laboratory of Biochemistry, NCCR, University of Neuchâtel, Rue Emile-Argand 9, CH-2007, Neuchâtel 7, Switzerland. salicylic acid (SA), jasmonic acid (JA), and ethylene (ET) play key roles in the regulation of defense responses, because plant genotypes that are affected in their response to any of these signals are more susceptible to infection by certain virulent pathogens.

Evidence for the role of SA in basal resistance came from the analysis of transgenic plants expressing the bacterial salicylate hydroxylase $(N a h G)$ gene (Gaffney et al. 1993). Salicylate hydroxylase inactivates SA by converting it to catechol. NahG tobacco plants were found to be more susceptible to Tobacco mosaic virus (TMV), the bacterium Pseudomonas syringae pv. tabaci, and the fungus Cercospora nicotianae (Delaney et al. 1994). Reducing the biosynthesis of, or sensitivity to, either JA or ET can also render plants more susceptible to pathogens and even insects. For instance, ET-insensitive tobacco plants transformed with the mutant etrl-1 gene from Arabidopsis lost their ability to resist the soilborne oomycete Pythium sylvaticum (Knoester et al. 1998). Similarly, Arabidopsis mutants affected in JA biosynthesis or signaling are more susceptible to Pythium mastophorum (Vijayan et al. 1998) and Pythium irregulare (Staswick et al. 1998), as well as insect herbivory (McConn et al. 1997).

In Arabidopsis, SA, JA, and ET are involved to different extents in basal resistance against specific pathogens. Basal resistance against the oomycetous pathogen Peronospora parasitica and to Turnip crinkle virus (TCV) is controlled predominantly by a SA-dependent pathway. Only SA-nonaccumulating NahG plants exhibited enhanced disease susceptibility to these pathogens (Delaney et al. 1994; Kachroo et al. 2000), whereas mutants affected in JA or ET signaling did not (Kachroo et al. 2000; Thomma et al. 1998). In contrast, basal resistance against the fungal pathogens Alternaria brassicicola and Botrytis cinerea was reduced only in JA- and ET-insensitive mutants and not in NahG plants (Thomma et al. 1998, 1999a). Interestingly, basal resistance against the bacterial pathogen Pseudomonas syringae pv. tomato DC3000 was found to be affected in both NahG plants and in JA- and ET-response mutants (Pieterse et al. 1998), suggesting that basal resistance against this pathogen is controlled by a combined action of SA, $\mathrm{JA}$, and ET.

Besides basal resistance responses that act at the site of pathogen infection, plants are capable of developing a systemic resistance that is effective against further pathogen infections. This induced disease resistance is generally manifested as a reduction of disease and a restriction of colonization of the challenging pathogen in comparison to nonstimulated control plants (Hammerschmidt 1999). The classical way of inducing resistance is by predisposal infection with a necrotizing pathogen, 
which gives rise to an enhanced defensive capacity in distal plant parts. This type of systemically induced resistance is generally referred to as systemic acquired resistance (SAR) (Ryals et al. 1996). The signaling pathway of pathogen-induced SAR depends on the endogenous accumulation of SA, because transgenic NahG plants have lost their ability to express SAR (Gaffney et al. 1993). The expression of SAR, triggered by either pathogen infection or treatment with SA or its functional analogues 2,6-dichloroisonicotinic acid (INA) or benzothiodiazole, is tightly associated with the transcriptional activation of genes encoding pathogenesis-related proteins (PRs) (Van Loon 1997).

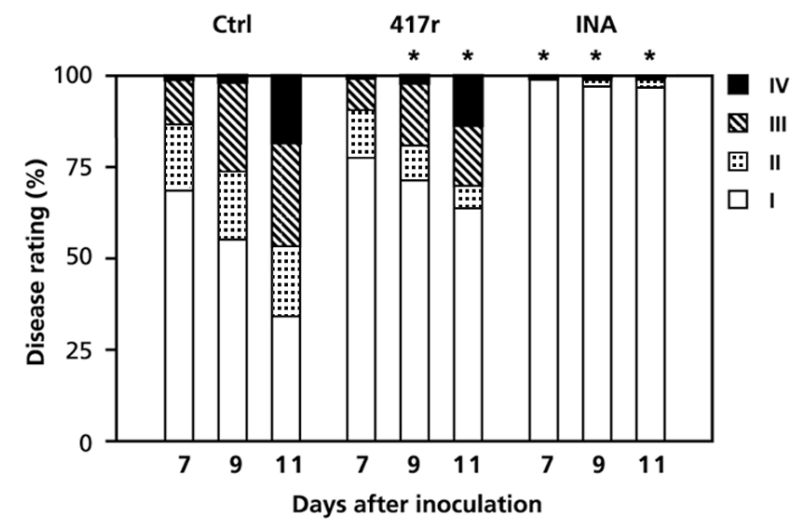

Fig. 1. Quantification of induced systemic resistance (ISR) and systemic acquired resistance (SAR) against Peronospora parasitica WACO9. ISR was induced by growing Arabidopsis Col-0 plants in soil containing Pseudomonas fluorescens WCS417r bacteria. SAR was induced by spraying plants with $0.1 \mathrm{mM}$ 2,6-dichloroisonicotinic acid (INA) 3 days before challenge. Plants were challenge-inoculated when 3 weeks old. At 7 , 9, and 11 days after challenge, disease severity was determined. Disease rating is expressed as the percentages of leaves falling in the following classes: I, no sporulation; II, $<50 \%$ of the leaf area covered by sporangiophores; III, $>50 \%$ of the leaf area covered by sporangiophores; and IV, leaf area heavily covered with sporangiophores, with additional chlorosis and leaf collapse. Asterisks indicate statistically significant different distributions of the disease-severity classes compared with the noninduced control treatments (Chi-square, $\alpha=0.05$ ).

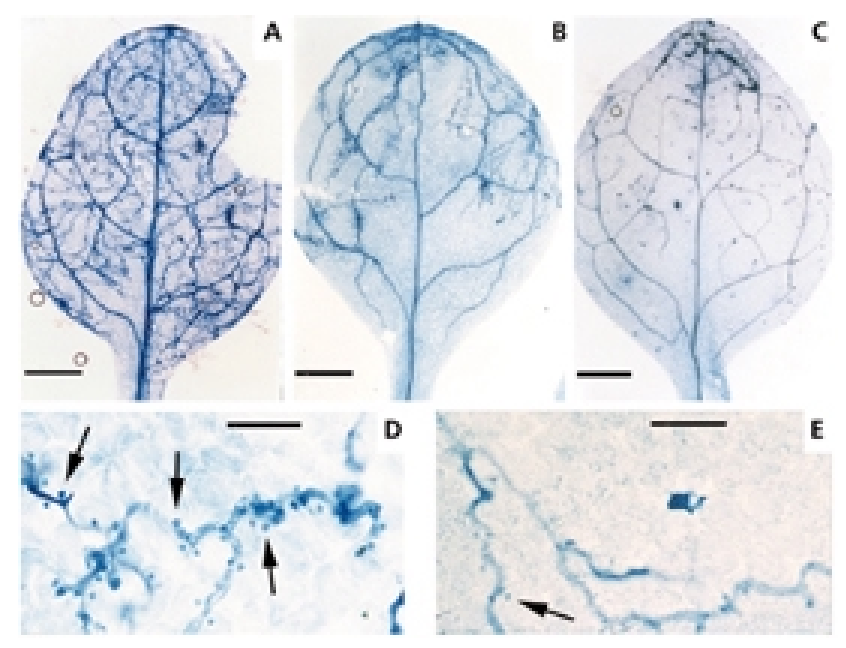

Fig. 2. Colonization of leaves of induced systemic resistance (ISR)- and systemic acquired resistance (SAR)-expressing Arabidopsis Col-0 plants by Peronospora parasitica WACO9. Leaves of A, water-treated plants; B, Pseudomonas fluorescens WCS417r-treated plants; and C, 2,6-dichloroisonicotinic acid (INA)-treated plants were stained with lactophenol trypan-blue at 9 days after challenge inoculation (scale bar $=0.5 \mathrm{~mm}$ ). The hyphae of $P$. parasitica $\mathbf{E}$, on ISR-expressing plants showed significantly less haustoria than did those $\mathbf{D}$, in control-treated plants (scale bar $=50 \mu \mathrm{m})$. Arrows indicate haustoria.
Another form of systemic resistance is triggered by selected strains of nonpathogenic rhizobacteria. To facilitate distinguishing this type of induced resistance from pathogen-induced SAR, the term rhizobacteria-mediated induced systemic resistance (ISR) was introduced (Pieterse et al. 1996, 2001; Van Loon et al. 1998). In Arabidopsis, ISR triggered by the root-colonizing bacterial strain Pseudomonas fluorescens WCS417r was shown to be effective against the fungal root pathogen Fusarium oxysporum f. sp. raphani and the bacterial leaf pathogen Pseudomonas syringae pv. tomato DC3000 (Pieterse et al. 1996). The signaling pathway controlling WCS417r-mediated ISR clearly differs from the SAR pathway in that it is independent of SA but requires responsiveness to JA and ET (Pieterse et al. 1996, 1998). Furthermore, the expression of WCS417r-mediated ISR is not accompanied by transcriptional activation of genes encoding PRs or other known defense-related genes (Pieterse et al. 1996; Van Wees et al. 1997). Interestingly, simultaneous
A

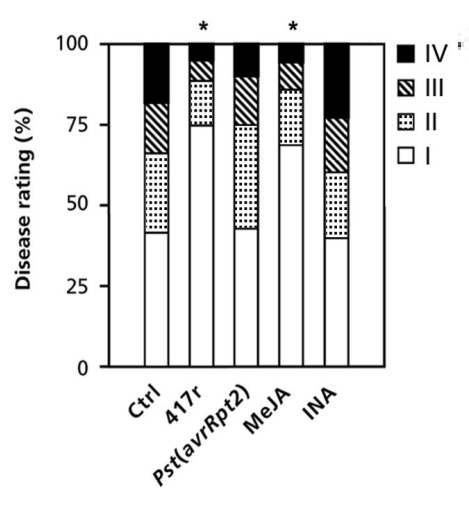

C

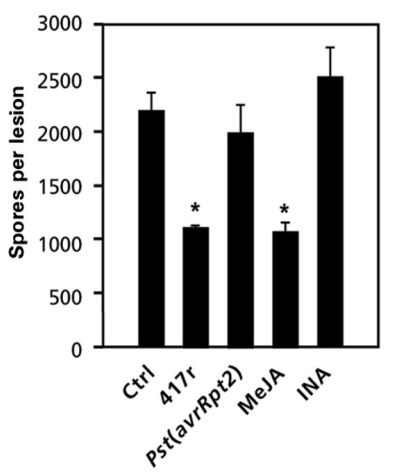

B

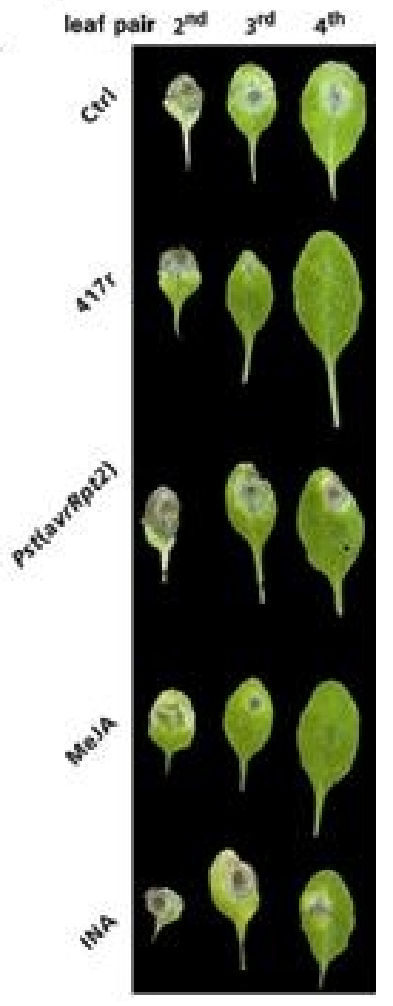

Fig. 3. Quantification of induced systemic resistance (ISR) and systemic acquired resistance (SAR) against Alternaria brassicicola MUCL 20297. ISR was induced by growing mutant pad3-1 plants in soil containing Pseudomonas fluorescens WCS417r bacteria or by spraying with $100 \mu \mathrm{M}$ methyl jasmonate (MeJA) 3 days before challenge. SAR was induced by pressure infiltrating the first pair of true leaves with a suspension of Pseudomonas syringae pv. tomato DC3000(avrRpt2) or by spraying with $0.1 \mathrm{mM}$ 2,6-dichloroisonicotinic acid (INA) 3 days before challenge. Plants $(n=25)$ were challenge-inoculated with A. brassicicola when 4 weeks old by applying 3- $\mu$ l droplets containing $10^{6}$ spores per $\mathrm{ml}$ on the second, third, and fourth pair of true leaves. A, Distribution of disease severity classes at 4 days after challenge. Disease severity is expressed as severity of disease symptoms and lesion size (increasing severity from I to IV; for details in text). Asterisks indicate statistically significant different distributions of the disease-severity classes compared with the noninduced control treatment (Chi-square, $\alpha=0.05$ ). B, Lesion development on the second, third, and fourth pair of true leaves 7 days after challenge with $A$. brassicicola. C, Average number of newly formed spores per lesion $( \pm$ standard error of the mean) at 7 days after challenge. Asterisks indicate statistically significant differences compared with the noninduced control treatment (Student's $t$ test, $\alpha=0.05$ ). 
activation of both the JA/ET-dependent ISR pathway and the SA-dependent SAR pathway results in an enhanced level of protection against Pseudomonas syringae pv. tomato DC3000, demonstrating that the defense responses activated via both pathways are compatible and additive (Van Wees et al. 2000).

The differential effectiveness of SA-dependent basal resistance, on the one hand, and JA- and ET-dependent basal resistance, on the other hand, prompted us to compare the spectrum of effectiveness of ISR and SAR. To this end, we examined the effectiveness of WCS417r-mediated ISR and SAR against $P$. parasitica and TCV (primarily resisted through SA-dependent basal resistance; Delaney et al. 1994; Kachroo et al. 2000) and against $A$. brassicicola (primarily resisted through JA-dependent basal resistance; Thomma et al. 1998). In addition, we analyzed the effectiveness of ISR and SAR against the bacterial leaf pathogen Xanthomonas campestris pv. armoraciae that, like Pseudomonas syringae pv. tomato DC3000, was resisted through a combination of SA-, JA-, and ET-dependent defenses in noninduced plants.

\section{RESULTS}

\section{Differential effectiveness of ISR and SAR against $P$. parasitica.}

To compare the effectiveness of SA-dependent SAR and JA/ET-dependent ISR against the oomycetous leaf pathogen $P$. parasitica, the level of protection against race WACO9 was assessed in SAR- and ISR-expressing Col-0 plants. ISR was triggered by growing plants in soil containing ISR-inducing Pseudomonas fluorescens WCS417r bacteria, whereas SAR was induced by spraying the leaves with INA. On leaves of control-treated plants, the first sporangiophores started to appear 6 to 7 days after challenge inoculation. Figure 1 shows that, by 11 days, $65 \%$ of the inoculated leaves showed sporulation. In WCS417r-treated plants, disease development was suppressed, leading to a statistically significant reduction in the number of leaves with sporulation at 9 and 11 days after challenge. Furthermore, the number of sporangia produced per gram of infected tissue was reduced sevenfold on the ISRexpressing leaves compared with the control plants $\left(10.8 \times 10^{5}\right.$ versus $1.5 \times 10^{5}$ sporangia per $g$ fresh weight in control and ISR-expressing plants, respectively). As shown in Figure 2A and B, ISR-expressing leaves allowed considerably less colonization by the pathogen than did leaves of noninduced plants. Furthermore, the hyphae in ISR-expressing leaves developed fewer haustoria compared with the hyphae in leaves of the control plants (Fig. 2D and E). This difference was apparent in all leaves that allowed pathogen colonization, irrespective of the extent of disease severity.

Consistent with previous findings (Uknes et al. 1992), treatment with INA induced a high level of SAR against $P$. parasitica, as evidenced by a $98 \%$ decrease in the number of leaves showing sporulation and a 13 -fold lower number of sporangia per gram of infected tissue 11 days after inoculation $(10.8 \times$ $10^{5}$ versus $0.8 \times 10^{5}$ sporangia per $\mathrm{g}$ fresh weight in control and SAR-expressing plants, respectively). Furthermore, colonization of SAR-expressing leaves by the pathogen was arrested predominantly at the stage of spore germination (Fig. 2A and C). These findings indicate that both ISR and SAR are effective against $P$. parasitica but that INA-induced SAR is significantly more effective than WCS417r-mediated ISR.

\section{Differential effectiveness of ISR and SAR against $A$. brassicicola.}

Wild-type Arabidopsis Col-0 plants are resistant against the necrotrophic fungus A. brassicicola (Thomma et al. 1999b). However, the phytoalexin-deficient mutant pad3-1 is suscepti- ble (Thomma et al. 1999b). Mutant pad3-1 plants are unaffected in their ability to express WCS417r-mediated ISR and SAR against Pseudomonas syringae pv. tomato DC3000 (C. M. J. Pieterse, unpublished data). Therefore, the effectiveness of ISR and SAR against A. brassicicola was assessed in this mutant. In noninduced pad3-1 plants, necrotic lesions appeared on the second leaf pair within 3 days after inoculation. By 7 days after inoculation, the third and fourth leaf pairs developed spreading lesions surrounded by chlorosis, and the second leaf pair displayed extensive tissue damage and concurrent sporulation by the pathogen. Induction of ISR by WCS417r protected the plants substantially against fungal invasion, as was evident from reduced lesion expansion (Fig. 3A and B) and a twofold reduction in fungal sporulation (Fig. 3C). By contrast, pathogen-induced SAR failed to reduce the spread and sporulation of the pathogen (Fig. 3).

Besides biological induction of ISR and SAR, chemical induction was tested by exogenous application of the chemical agents methyl jasmonate (MeJA) and INA, which were previously demonstrated to activate the ISR and the SAR pathway, respectively (Pieterse et al. 1998; Vernooij et al. 1995). Treatment of the leaves with MeJA protected the plants significantly, whereas treatment of the leaves with INA did not (Fig. 3 ). The level of MeJA-induced protection was similar to that observed in WCS417r-treated plants. These findings indicate that, in contrast to SAR, expression of ISR is effective against infection by $A$. brassicicola.

\section{ISR and SAR are equally effective \\ against $X$. campestris pv. armoraciae.}

Little is known about the involvement of SA-, JA-, and ETdependent defense responses in basal resistance against $X$. campestris. Rogers and Ausubel (1997) reported that mutant eds5-1, which is allelic with the SA-deficient mutant sid1-1 (Nawrath and Métraux 1999), displays enhanced susceptibility to $X$. campestris pv. raphani. This indicates that in noninduced plants $X$. campestris is resisted, at least in part, through SAdependent defenses. To investigate the role of SA, JA, and ET in the basal resistance response against $X$. campestris pv. armoraciae, we determined growth of the pathogen in the leaves of noninduced Col-0 plants, SA-nonaccumulating NahG plants, JA-insensitive jarl-1 plants, and ET-insensitive ein2-1 plants. At 3 days after inoculation, NahG, jarl-1, and ein2-1 plants allowed three- to fivefold higher levels of growth of the pathogen in the leaves than did wild-type plants (data not shown), indicating that basal resistance against $X$. campestris pv. armoraciae is resisted through a combination of SA-, JA-, and ET-dependent defenses.

To investigate the effectiveness of induced resistance against $X$. campestris pv. armoraciae, accession Col-0 was tested for WCS417r-mediated ISR and pathogen-induced SAR against this pathogen. Treatment of the roots with WCS417r bacteria resulted in a statistically significant reduction of disease symptoms (Fig. 4A) and growth of the pathogen (Fig. 4B), demonstrating that WCS417r-mediated ISR effectively inhibits $X$. campestris pv. armoraciae infection. Similarly, pathogeninduced SAR resulted in a statistically significant suppression of disease symptoms (Fig. 4A) and pathogen growth (Fig. 4B) to the same level as found in the ISR-expressing plants. Thus, ISR and SAR are equally effective in protecting Arabidopsis against disease caused by $X$. campestris pv. armoraciae.

\section{ISR is ineffective against TCV.}

TCV is virulent on most Arabidopsis accessions, including Col-0 (Simon et al. 1992), but avirulent on accession Dijon (Di-0 and Di-17), which develops a hypersensitive response and does not allow systemic spreading of the pathogen 
(Dempsey et al. 1997; Simon et al. 1992). To compare the effectiveness of SAR and ISR against this pathogen, the level of induced protection was examined in the compatible interaction with Col-0 and the incompatible interaction with Di-0. In Col0 plants, disease incidence was determined by scoring the number of noninoculated leaves with symptoms, i.e., crinkled deformation and appearance of chlorotic spots around the vascular bundles. In addition, multiplication of TCV was assessed by gel blot analysis of RNA from systemically infected plants. In Col-0, INA treatment resulted in a $40 \%$ suppression of symptoms (Fig. 5A) and a substantial reduction of TCV RNA accumulation (Fig. 6A). In hypersensitively reacting Di-0 plants, the level of protection was assessed by determining the reduction in lesion size and the level of TCV RNA in locally infected leaves. Consistent with previous findings (Uknes et al. 1993), induction of SAR by INA resulted in a threefold reduction in lesion size (Fig. 5B) and a strong suppression of TCV RNA accumulation in Di-0 plants (Fig. 6A). These findings indicate that SAR effectively inhibits viral multiplication.

In contrast to INA-induced SAR, treatment of the roots with ISR-inducing WCS417r bacteria failed to suppress disease development (Fig. 5A and B) and viral RNA accumulation (Fig. 6A) in both Col-0 and Di-0 plants. Previously, we demonstrated that both the ET precursor 1-aminocyclopropane-1-carboxylate (ACC) and MeJA activate the ISR pathway (Pieterse et al. 1998). Therefore, we also tested the effect of exogenous application of these chemical agents on their ability to induce resistance against TCV. Neither ACC treatment nor MeJA treatment of either Col-0 or Di- 0 plants resulted in a reduction of disease symptoms (Fig. 5C and D) or viral RNA accumulation (Fig. 6B). Thus, in contrast to SA-dependent SAR, JA/ET-dependent ISR is not effective against this virus.
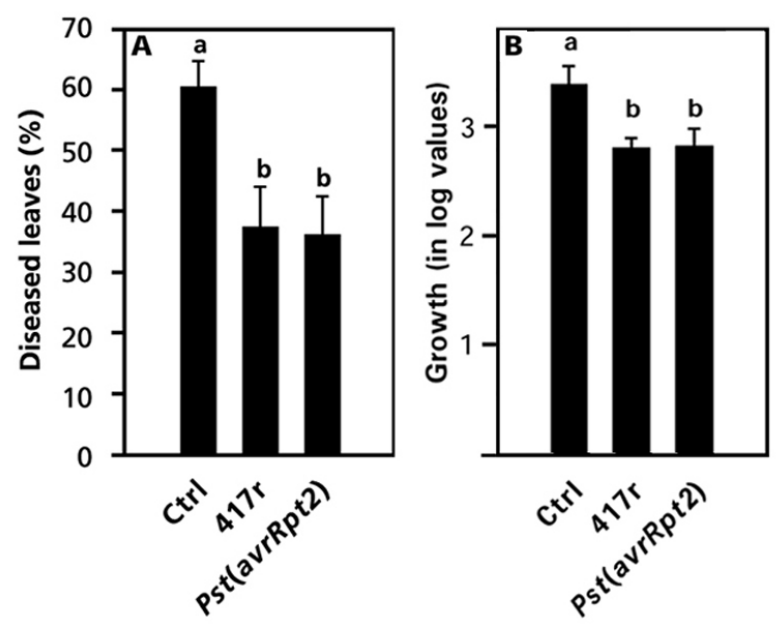

Fig. 4. Quantification of induced systemic resistance (ISR) and systemic acquired resistance (SAR) against Xanthomonas campestris pv. armoraciae. ISR was induced by growing Arabidopsis Col-0 plants in soil containing Pseudomonas fluorescens WCS417r bacteria. SAR was induced by pressure-infiltrating a suspension of avirulent Pseudomonas syringae pv. tomato DC3000(avrRpt2) into the first two leaves 3 days prior to challenge inoculation of the upper leaves. Five-week-old plants were challenge-inoculated by dipping the leaves in a bacterial suspension at $10^{8} \mathrm{CFU} / \mathrm{ml}$. A, Disease symptoms were scored at 3 days after challenge and quantified as the proportion of leaves with symptoms. Different letters indicate statistically significant differences between treatments (Fisher's least significant difference test; $\alpha=0.05, n=20$ to $25)$. B, Bacterial growth in the leaves was determined over a 3-day time interval. Values presented are means ( \pm standard deviation) of the log of the growth values. Different letters indicate statistically significant differences between treatments (Fisher's least significant difference test; $\alpha=0.05, n=5$ ).

\section{DISCUSSION}

WCS417r-mediated ISR and pathogen-induced SAR are two inducible defense responses that are controlled by distinct signaling pathways (Pieterse et al. 1998). In this study, we tested both types of induced resistance in Arabidopsis for their effectiveness against an oomycete, a fungus, a bacterium, and a virus. ISR and SAR were equally effective against $X$. campestris pv. armoraciae (Fig. 4). However, the effectiveness of ISR and SAR against $P$. parasitica, A. brassicicola, and TCV diverged. Induction of SAR resulted in a high level of protection against $P$. parasitica and TCV (Figs. 1, 2, 5, and 6), whereas WCS417r-mediated ISR yielded only moderate protection against $P$. parasitica (Figs. 1 and 2 ) and no protection against TCV (Figs. 5 and 6). Conversely, ISR was effective against $A$. brassicicola, whereas SAR was not (Fig. 3).

By using Arabidopsis genotypes affected in their response to either SA, JA, or ET, it was previously demonstrated that basal resistance against $P$. parasitica and TCV is predominantly conferred by SA-dependent defense responses (Delaney et al. 1994; Kachroo et al. 2000), whereas basal resistance against $A$. brassicicola is mainly controlled by JA, and to a lesser extent by ET (Thomma et al. 1998, 1999a). Like Pseudomonas syringae pv. tomato DC3000 (Pieterse et al. 1998), X. campestris pv. armoraciae proliferates faster in NahG, jarl-1, and ein2-1 plants than in wild-type Col-0 plants (data not shown), indicating that basal resistance against both bacterial pathogens is controlled by a combination of SA-, JA-, and ET-dependent pathways. When relating the effectiveness of ISR and SAR against these pathogens to the defense pathways that contribute to basal resistance (Fig. 7), it is clear that SAR is effective against pathogens that are resisted through SA-dependent basal defenses, whereas WCS417r-mediated ISR is effective predominantly against pathogens that are resisted through JA/ETdependent defense responses. In view of the earlier notion that induced disease resistance is an enhancement of genetically determined extant resistance (Van Loon 1997), we hypothesize that SAR constitutes an enhancement of SA-dependent basal resistance, whereas WCS417r-mediated ISR involves an enhancement of JA- and ET-dependent basal resistance.

If SAR is an enhancement of SA-dependent basal resistance, one may expect that SA-dependent responses are activated more strongly or more rapidly upon challenge of SAR-expressing plant parts. Similarly, JA- and ET-dependent responses should be boosted upon challenge of plants expressing WCS417rmediated ISR. Indeed, SAR-expressing leaves of Arabidopsis show a potentiated expression of the SA-inducible genes $P R-1$, $P R-2$, and $P R-5$ after challenge inoculation with Pseudomonas syringae pv. tomato DC3000, whereas this potentiation was absent for the JA-inducible genes PDF1.2 and AtVSP (Van Wees et al. 1999). Conversely, challenge-inoculated, ISR-expressing Arabidopsis leaves showed potentiated expression of AtVSP, while no potentiation was detected for the SA-inducible $P R$ genes (Van Wees et al. 1997).

Consistent with earlier findings (Uknes et al. 1993), we showed that expression of INA-induced SAR limits TCV RNA accumulation and disease symptom development. However, no such effects were evident upon treatment with WCS417r, demonstrating that WCS417r-mediated ISR is not effective against TCV. Over the past years, there have been several reports showing that rhizobacteria-mediated ISR effectively inhibits infection by viral pathogens. In tobacco, Pseudomonas fluorescens CHA0 induced resistance against Tobacco necrosis virus (TNV) (Maurhofer et al. 1994), while Pseudomonas aeruginosa 7NSK2 triggered resistance against TMV (De Meyer et al. 1999). However, in both cases, the mechanisms of induced resistance appeared to depend on SA. The resistance induced 
by strain CHA0 coincided with systemic accumulation of SA and PRs in the plant (Maurhofer et al. 1994), and two SA-deficient mutants of strain 7NSK2 were no longer capable of inducing resistance against TMV (De Meyer et al. 1999). Furthermore, Maurhofer and colleagues (1998) demonstrated that introduction of the SA biosynthetic gene cluster of strain CHA0 into the SA-nonproducing Pseudomonas fluorescens strain P3 significantly improved its ability to induce systemic resistance against TNV. These observations indicate that both these cases of rhizobacteria-mediated ISR against viral pathogens are phenotypically and mechanistically similar to pathogen-induced SAR, with SA implicated as the inducing determinant.

Recently, it was suggested that SA-dependent resistance against viruses is achieved through a signaling pathway that partially differs from SA-dependent resistance acting against pathogenic fungi and bacteria (Murphy et al. 1999). This difference may be related to the intimate intracellular relationship between viruses and their hosts, as opposed to the extracellularly attacking fungi and bacteria. In our experiments, TCV was the only pathogen tested that was entirely insensitive to WCS417r-mediated ISR. This suggests that TCV is either completely insensitive to the mechanisms of WCS417r-medi-
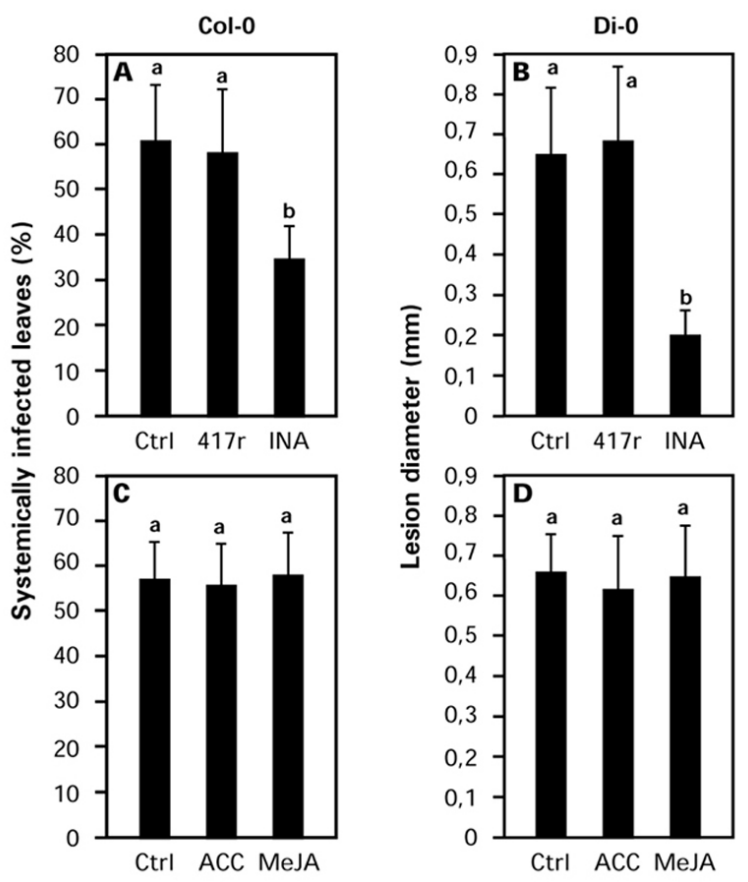

Fig. 5. Quantification of induced systemic resistance (ISR) and systemic acquired resistance (SAR) against Turnip crinkle virus (TCV) in Arabidopsis Col-0 and Di-0 plants. ISR was induced by growing plants in soil containing Pseudomonas fluorescens WCS417r bacteria. SAR was induced by spraying the plants with $0.1 \mathrm{mM}$ 2,6-dichloroisonicotinic acid (INA) 3 days before challenge inoculation. Treatments with methyl jasmonate (MeJA) and 1-aminocyclopropane-1-carboxylate (ACC) were performed 3 days before challenge inoculation by dipping the leaves in a solution containing either $0.1 \mathrm{mM}$ MeJA or $1 \mathrm{mM}$ ACC. Four-week-old plants were challenge-inoculated by rubbing 3- $\mu$ l droplets of TCV RNA $(0.1 \mu \mathrm{g} / \mu \mathrm{l})$ in bentonite buffer onto three lower leaves. For Di-0, average lesion diameters of challenged leaves $(n=45)$ were measured 4 days later. For Col-0, the percentage of noninoculated leaves with symptoms was determined per plant $(n=20) 11$ days later. Noninoculated leaves showing crinkled deformation of the leaves and chlorotic spots around the vascular bundles were scored as diseased. For each accession, different letters indicate statistically significant differences between treatments (Fisher's least significant difference test, $\alpha=0.05$ ). A, ISR and SAR in susceptible Col-0 plants. B, ISR and SAR in hypersensitive response (HR)-developing Di-0 plants. C, ACC- and MeJA-induced protection in susceptible Col-0 plants. D, ACC- and MeJA-induced protection in HRdeveloping Di-0 plants. ated ISR or that the virus is located at sites where these mechanisms are not active.

Our results clearly demonstrate that SA-dependent and JA/ET-dependent induced resistance have different specificities. SA-dependent SAR is effective against pathogens that in noninduced plants are resisted through SA-dependent defenses, whereas ISR is effective against pathogens that in noninduced plants are resisted through JA/ET-dependent defenses. This indicates that induced resistance constitutes a reinforcement of extant SA- or JA/ET-dependent basal defenses. This is novel because the general notion is that induced resistance functions superimposed on, and independently of, other types of resistance, i.e., constitutive basal resistance and $R$ gene-mediated resistance. The observation that some pathogens are sensitive to components of both the SAR and ISR pathways offers potential for improved disease control, as was already demonstrated by the additive effect of SAR and rhizobacteria-mediated ISR on the level of induced protection against Pseudomonas syringae pv. tomato DC3000 (Van Wees et al. 2000).

\section{MATERIALS AND METHODS}

Cultivation of plants, rhizobacteria, and pathogens.

Arabidopsis thaliana accessions Columbia (Col-0) and Dijon (Di-0), transgenic NahG plants harboring the bacterial $N a h G$ gene (Delaney et al. 1994), the phytoalexin-deficient Col-0 mutant pad3-1 (Glazebrook and Ausubel 1994), the JAinsensitive Col-0 mutant jarl-1 (Staswick et al. 1992), and the ET-insensitive Col-0 mutant ein2-1 (Guzman and Ecker 1990) were sown in quartz sand. Two-week-old seedlings were transferred to $60-\mathrm{ml}$ pots containing a sand/potting soil mixture that had been autoclaved twice for 20 min. Plants were further cultivated, as described by Ton and colleagues (1999).

For treatment of the roots with ISR-inducing rhizobacteria, Pseudomonas fluorescens WCS417r (Pieterse et al. 1996) was grown on King's medium B agar plates (King et al. 1954) for $24 \mathrm{~h}$ at $28^{\circ} \mathrm{C}$. Bacterial cells were collected and resuspended in $10 \mathrm{mM} \mathrm{MgSO}_{4}$ to a final density of $10^{9} \mathrm{CFU} / \mathrm{ml}$. For induction of SAR, Pseudomonas syringae pv. tomato DC3000 carrying the avirulence gene avrRpt2 (Kunkel et al. 1993) was cultured overnight at $28^{\circ} \mathrm{C}$ in liquid King's medium B supplemented

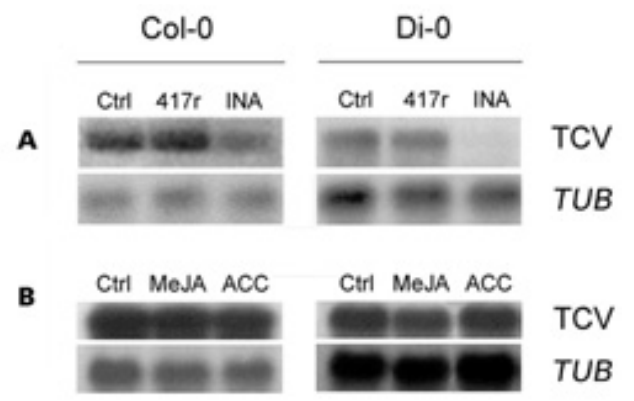

Fig. 6. Accumulation of Turnip crinkle virus (TCV) RNA in Arabidopsis Col-0 and Di-0 plants after treatment with Pseudomonas fluorescens WCS417r, 2,6-dichloroisonicotinic acid (INA), methyl jasmonate (MeJA), or 1-aminocyclopropane-1-carboxylate (ACC). ISR was induced by growing plants in soil containing Pseudomonas fluorescens WCS417r bacteria. SAR was induced by spraying the plants with 0.1 mM INA 3 days before challenge inoculation. Treatments with MeJA and ACC were performed 3 days before challenge inoculation by dipping the leaves in a solution containing either $0.1 \mathrm{mM}$ MeJA or $1 \mathrm{mM}$ ACC. Four-week-old plants were challenge-inoculated by rubbing $3-\mu \mathrm{l}$ droplets of TCV RNA $(0.1 \mu \mathrm{g} / \mu \mathrm{l})$ in bentonite buffer onto three lower leaves. For Di-0, the inoculated leaves were harvested at 4 days after challenge. For Col-0, the noninoculated, systemically infected leaves were harvested 11 days after challenge. Blots were hybridized with TCV-specific probes derived from a TCV cDNA clone. 
with $25 \mathrm{mg}$ of kanamycin per liter. Bacterial cells were collected by centrifugation and resuspended in $10 \mathrm{mM} \mathrm{MgSO}$ to a final density of $10^{7} \mathrm{CFU} / \mathrm{ml}$.

$P$. parasitica WACO9 sporangia were obtained by washing sporulating Col-0 leaves in $10 \mathrm{mM} \mathrm{MgSO}$, collected by centrifugation, and resuspended in $10 \mathrm{mM} \mathrm{MgSO}_{4}$ to a final density of $5 \times 10^{4}$ sporangia per ml. A. brassicicola MUCL 20297 was grown on potato dextrose agar plates for 2 weeks at $22^{\circ} \mathrm{C}$. Conidia were harvested, as described by Broekaert and colleagues (1990). Rifampicin-resistant $X$. campestris pv. armoraciae (Sahin and Miller 1996) was cultured overnight at $28^{\circ} \mathrm{C}$ in liquid $0.8 \%$ nutrient broth medium (Difco, Detroit), collected by centrifugation, and resuspended in $10 \mathrm{mM} \mathrm{MgSO}_{4}$ to a final density of $10^{8} \mathrm{CFU} / \mathrm{ml}$. TCV inoculum was produced by in vitro transcription from plasmid pT7TCV66 (Oh et al. 1995) and adjusted to a concentration of $0.1 \mu \mathrm{g}$ of RNA per $\mu$.

\section{Induction treatments.}

ISR was induced by transplanting 2-week-old Arabidopsis seedlings to soil supplemented with a suspension of WCS417r bacteria to a final density of $5 \times 10^{7} \mathrm{CFU} / \mathrm{g}$ as described by Pieterse and colleagues (1996). Induction of SAR was performed 3 days before challenge inoculation, either by pressureinfiltrating the first pair of true leaves with Pseudomonas syringae pv. tomato $\mathrm{DC} 3000\left(\right.$ avrRpt2) at $10^{7} \mathrm{CFU} / \mathrm{ml}$ or by spraying the plants with $0.1 \mathrm{mM}$ INA (Syngenta, Basel, Switzerland), formulated as $25 \%$ active ingredient with $57 \mathrm{mg}$ of wettable powder per liter. Treatments with the ET precursor ACC and MeJA were performed at 3 days before challenge inoculation by dipping the leaves in a solution of $0.015 \%$ (vol/vol) Silwet L77 (Van Meeuwen Chemicals B.V., Weesp, The Netherlands), containing either $0.1 \mathrm{mM} \mathrm{MeJA}$ or $1 \mathrm{mM}$ ACC. MeJA treatment prior to challenge with A. brassicicola was performed by spraying the leaves with $0.1 \mathrm{mM}$ MeJA formulated with $57 \mathrm{mg}$ of wettable powder per liter. Controltreated plants were either dipped in a solution containing $0.015 \%$ (vol $/ \mathrm{vol}$ ) Silwet L77 or sprayed with $57 \mathrm{mg}$ of wettable powder per liter.

\section{$P$. parasitica bioassays.}

Three-week-old Col-0 plants were challenge-inoculated with P. parasitica by applying 3- $\mu$ drops of $10 \mathrm{mM} \mathrm{MgSO}_{4}$ containing $5 \times 10^{4}$ sporangia per $\mathrm{ml}$ on the first four true leaves. Inoculated plants were maintained at $17^{\circ} \mathrm{C}$ and $100 \%$ relative humidity. Disease symptoms were scored for about 200 leaves

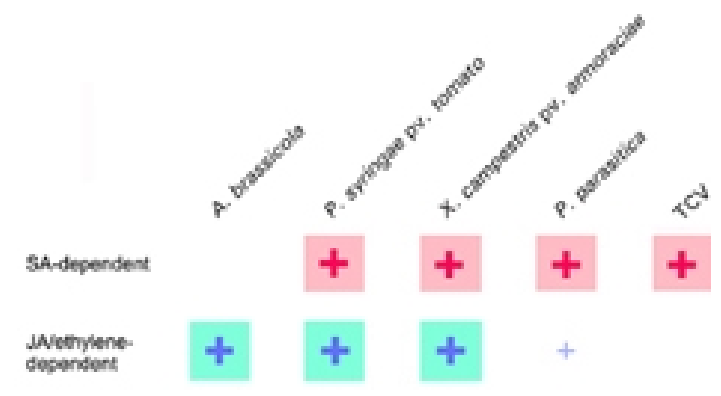

Fig. 7. Relationship between induced resistance and basal resistance against different Arabidopsis pathogens. Systemic acquired resistance (SAR) (red plus signs) is effective against pathogens that in noninduced plants are resisted through salicylic acid (SA)-dependent basal defense responses (pink squares), whereas Pseudomonas fluorescens WCS417rmediated induced systemic resistance (ISR) (blue plus signs) is mainly effective against pathogens that in noninduced plants are resisted through jasmonic acid (JA)/ethylene (ET)-dependent basal defense responses (green squares). From this, we postulate that SAR constitutes an enhancement of extant SA-dependent basal defenses, whereas ISR involves the enhancement of extant JA/ET-dependent basal defenses. per treatment at 7,9, and 11 days after challenge. Disease rating was expressed as intensity of disease symptoms and pathogen sporulation on each leaf: I, no sporulation; II, $<50 \%$ of the leaf area covered by sporangiophores; III, $>50 \%$ of the leaf area covered by sporangiophores; and IV, leaf area heavily covered with sporangiophores, with additional chlorosis and leaf collapse. Leaves were washed in $10 \mathrm{mM} \mathrm{MgSO}_{4}$, and sporangia were collected by centrifugation at $1.500 \times g$ for $2 \mathrm{~min}$ and resuspended in $10 \mathrm{mM} \mathrm{MgSO}$. The number of sporangia was determined microscopically, using a hemacytometer. For determining leaf colonization, infected leaves were stained with lactophenol trypan-blue and examined microscopically at 9 days after inoculation, as described by Koch and Slusarenko (1990).

\section{A. brassicicola bioassays.}

Four-week-old pad3-1 plants $(n=25)$ were challenge-inocu-

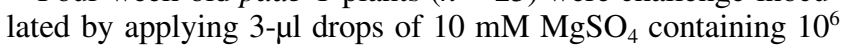
spores per $\mathrm{ml}$ on the second, third, and fourth pair of true leaves of each plant. Inoculated plants were kept at $100 \%$ relative humidity. Disease severity was determined by measuring the diameters of the lesions 3 and 4 days after challenge. Disease rating was expressed as intensity of disease symptoms and lesion size: I, no visible disease symptoms; II, nonspreading lesion with a diameter $<1.5 \mathrm{~mm}$; III, spreading lesion with a diameter ranging between 1.5 and $7 \mathrm{~mm}$, surrounded by a chlorotic halo; and IV, spreading lesion with a diameter $>7 \mathrm{~mm}$ with extensive tissue maceration and sporulation by the pathogen. Isolation and determination of the number of newly formed spores were performed essentially as described by Thomma and colleagues (1999b). Batches of 15 leaves from five plants were placed in $9 \mathrm{ml}$ of $0.1 \%$ (vol/vol) Tween 20 in a test tube. After vigorous shaking, the leaves were removed from the suspension. The spore suspension was centrifuged at $3.200 \times g$ for $15 \mathrm{~min}$, and spores were resuspended in $100 \mu \mathrm{l}$ of $0.1 \%$ ( $\mathrm{vol} / \mathrm{vol})$ Tween 20 and counted in a hemacytometer.

\section{X. campestris bioassays.}

Five-week-old plants were inoculated by dipping the leaves in a suspension of $X$. campestris pv. armoraciae containing $10^{8}$ $\mathrm{CFU} / \mathrm{ml}$ in $10 \mathrm{mM} \mathrm{MgSO}_{4}$ and $0.015 \%$ (vol/vol) Silwet L-77. Three days after challenge inoculation, the percentage of leaves with symptoms was determined per plant ( $n=20$ to 25). Leaves showing necrotic or water-soaked lesions surrounded by chlorosis were scored as diseased. Growth of $X$. campestris pv. armoraciae in the leaves of wild-type Col-0, transgenic NahG, and mutant jarl-1 and ein2-1 plants was determined by collecting replicate samples from five plants per treatment or genotype. Immediately after challenge inoculation and 3 days later, leaf samples were collected, weighed, rinsed in water, and homogenized in $10 \mathrm{mM} \mathrm{MgSO}_{4}$. Serial dilutions were plated on selective King's medium B agar and supplemented with $100 \mathrm{mg}$ of cycloheximide per liter and $50 \mathrm{mg}$ of rifampicin per liter. After incubation at $28^{\circ} \mathrm{C}$ for 2 days, the number of rifampicin-resistant CFU per gram of infected leaf tissue was determined, and bacterial growth over a 3-day time interval was calculated.

\section{TCV bioassays.}

Four-week-old Arabidopsis Col-0 and Di-0 plants were challenge-inoculated by applying 3- $\mu$ l droplets of TCV RNA $(0.1 \mu \mathrm{g} / \mu \mathrm{l})$ in bentonite buffer $\left(0.05 \mathrm{M}\right.$ glycine, $0.03 \mathrm{M} \mathrm{K}_{2} \mathrm{HPO}_{4}$, $0.02 \mathrm{~g}$ of bentonite per $\mathrm{ml}$ ) on three lower leaves. Droplets were rubbed across the leaf surface with a glass rod, and the inoculated leaves were marked. For Di-0, lesion diameters on the inoculated leaves $(n=45)$ were determined under a dissection microscope 4 days after challenge. Subsequently, chal- 
lenged leaves were collected for gel blot analysis of viral RNA accumulation. For Col- 0 , the percentage of noninoculated leaves with symptoms was determined per plant $(n=20$ to 25) 11 days after challenge. Unchallenged leaves showing crinkled deformation of the leaves and chlorotic spots around the vascular bundles were scored as diseased. Subsequently, aboveground parts of five plants per treatment were collected for gel blot analysis of viral RNA accumulation.

\section{RNA gel blot analysis.}

Extraction of total RNA and preparation of RNA gel blots were performed as described (Van Wees et al. 1999). RNA gel blots were hybridized with a TCV-specific probe. To check for equal loading, the blots were stripped and hybridized with a probe for the constitutively expressed $\beta$-tubulin $(T U B)$ gene. Probes for the detection of TCV RNA were derived from the cDNA clone on plasmid pT7TCV66 (Oh et al. 1995). Probes for detection of $T U B$ transcripts were prepared by polymerase chain reaction with primers based on the sequence of Arabidopsis obtained from GenBank accession no. M21415.

\section{ACKNOWLEDGMENTS}

We thank I. van der Sluis for technical assistance and M. Aarts, B. Thomma, S. Miller, and A. Simon for kindly providing isolates of Peronospora parasitica, Alternaria brassicicola, Xanthomonas campestris pv. armoraciae, and Turnip crinkle virus, respectively.

\section{LITERATURE CITED}

Broekaert, W. F., Terras, F. R. G., Cammue, B. P. A., and Van Der Leyden, J. 1990. An automated quantitative assay for fungal growth. FEMS (Fed. Eur. Microbiol. Soc.) Microbiol. Lett. 69:55-60.

Delaney, T. P., Uknes, S., Vernooij, B., Friedrich, L., Weymann, K., Negrotto, D., Gaffney, T., Gur-Rella, M., Kessmann, H., Ward, E., and Ryals, J. 1994. A central role of salicylic acid in plant disease resistance. Science 266:1247-1250.

De Meyer, G., Audenaert, K., and Höfte, M. 1999. Pseudomonas aeruginosa 7NSK2-mediated induced systemic resistance in tobacco depends on in planta salicylic acid accumulation, but is not associated with $P R$ $1 a$ expression. Eur. J. Plant Pathol. 105:513-517.

Dempsey, D. A., Pathirana, M. S., Wobbe, K. K., and Klessig, D. F. 1997. Identification of an Arabidopsis locus required for resistance to turnip crinkle virus. Plant J. 11:301-311.

Gaffney, T. P., Friedrich, L., Vernooij, B., Negrotto, D., Neye, G., Uknes, S., Ward, E., Kessmann, H., and Ryals, J. 1993. Requirement of salicylic acid for the induction of systemic acquired resistance. Science 261:754-756.

Glazebrook, J., and Ausubel, F. M. 1994. Isolation of phytoalexin deficient mutants of Arabidopsis thaliana and characterization of their interactions with bacterial pathogens. Proc. Natl. Acad. Sci. U.S.A. 91: 8955-8959.

Guzman, P., and Ecker, J. R. 1990. Exploiting the triple response of Arabidopsis to identify ethylene-related mutants. Plant Cell 2:513-523.

Hammerschmidt, R. 1999. Induced disease resistance: How do induced plants stop pathogens? Physiol. Mol. Plant Pathol. 55:77-84.

Jackson, A. O., and Taylor, C. B. 1996. Plant-microbe interactions: Life and death at the interface. Plant Cell 8:1651-1668.

Kachroo, P., Yoshioka, K., Shah, J., Dooner, K. D., and Klessig, D. F. 2000. Resistance to turnip crinkle virus in Arabidopsis is regulated by two host genes and is salicylic acid dependent but NPR1, ethylene, and jasmonate independent. Plant Cell 12:677-690.

King, E. O., Ward, M. K., and Raney, D. E. 1954. Two simple media for the demonstration of phycocyanin and fluorescin. J. Lab. Clin. Med. 44:301-307

Knoester, M., Van Loon, L. C., Van den Heuvel, J., Hennig, J., Bol, J. F., and Linthorst, H. J. M. 1998. Ethylene-insensitive tobacco lacks nonhost resistance against soil-borne fungi. Proc. Natl. Acad. Sci. U.S.A. 95:1933-1937.

Koch, E., and Slusarenko, A. 1990. Arabidopsis is susceptible to infection by a downy mildew fungus. Plant Cell 2:437-445.

Kunkel, B. N., Bent, A., Dahlbeck, D., Innes, R. W., and Staskawicz, B. J. 1993. RPS2, an Arabidopsis disease resistance locus specifying recognition of Pseudomonas syringae strains expressing the avirulence gene avrRpt2. Plant Cell 5:865-875.
Maurhofer, M., Hase, C., Meuwly, P., Métraux, J.-P., and Défago, G. 1994. Induction of systemic resistance of tobacco to tobacco necrosis virus by the root-colonizing Pseudomonas fluorescens strain CHA0: Influence of the gacA gene and of pyoverdine production. Phytopathology 84:139-146.

Maurhofer, M., Reimmann, C., Schmidli-Sacherer, P., Heeb, S., Haas, D., and Défago, G. 1998. Salicylic acid biosynthesis genes expressed in Pseudomonas fluorescens strain P3 improve the induction of systemic resistance in tobacco against tobacco necrosis virus. Phytopathology 88:678-684.

McConn, M., Creelman, R. A., Bell, E., Mullet, J. E., and Browse, J. 1997. Jasmonate is essential for insect defense in Arabidopsis. Proc. Natl. Acad. Sci. U.S.A. 94:5473-5477.

Murphy, A. M., Chivasa, S., Singh, D. P., and Carr, J. P. 1999. Salicylic acid-induced resistance to viruses and other pathogens: A parting of the ways? Trends Plant Sci. 4:155-160.

Nawrath, C., and Métraux, J.-P. 1999. Salicylic acid induction-deficient mutants of Arabidopsis express $P R-2$ and $P R-5$ and accumulate high levels of camalexin after pathogen inoculation. Plant Cell 11:13931404.

Oh, J.-W., Kong, Q., Song, C., Carpenter, C. D., and Simon, A. E. 1995. Open reading frames of turnip crinkle virus involved in satellite symptom expression and incompatibility with Arabidopsis thaliana ecotype Dijon. Mol. Plant-Microbe Interact. 8:979-987.

Pieterse, C. M. J., Van Wees, S. C. M., Hoffland, E., Van Pelt, J. A., and Van Loon, L. C. 1996. Systemic resistance in Arabidopsis induced by biocontrol bacteria is independent of salicylic acid accumulation and pathogenesis-related gene expression. Plant Cell 8:1225-1237.

Pieterse, C. M. J., Van Wees, S. C. M., Van Pelt, J. A., Knoester, M., Laan, R., Gerrits, H., Weisbeek, P. J., and Van Loon, L. C. 1998. A novel signaling pathway controlling induced systemic resistance in Arabidopsis. Plant Cell 10:1571-1580.

Pieterse, C. M. J., Van Pelt, J. A., Van Wees, S. C. M., Ton, J., LéonKloosterziel, K. M., Keurentjes, J. J. B., Verhagen, B. W. M., Knoester, M., Van der Sluis, I., Bakker, P. A. H. M., and Van Loon, L. C. 2001. Rhizobacteria-mediated induced systemic resistance: Triggering, signalling, and expression. Eur. J. Plant Pathol. 107:51-61.

Rogers, E. E., and Ausubel, F. M. 1997. Arabidopsis enhanced disease susceptibility mutants exhibit enhanced susceptibility to several bacterial pathogens and alterations in $P R-1$ gene expression. Plant Cell 9: 305-316.

Ryals, J. A., Neuenschwander, U. H., Willits, M. G., Molina, A., Steiner, H., and Hunt, M. D. 1996. Systemic acquired resistance. Plant Cell 8: 1809-1819.

Sahin, F., and Miller, S. A. 1996. Occurrence and identification of a bacterial spot disease of radish in Ohio. Phytopathology (Abstr.) 86:S79.

Simon, A. E., Li, X. H., Lew, J. E., Stange, R., Zhang, C., Polacco, M., and Carpenter, C. D. 1992. Susceptibility and resistance of Arabidopsis thaliana to turnip crinkle virus. Mol. Plant-Microbe Interact. 5: 496-503.

Staswick, P. E., Yuen, G. Y., and Lehman, C. C. 1992. Methyl jasmonate inhibition of root growth and induction of a leaf protein are decreased in an Arabidopsis thaliana mutant. Proc. Natl. Acad. Sci. U.S.A. 89: 6837-6840.

Staswick, P. E., Yuen, G. Y., and Lehman, C. C. 1998. Jasmonate signaling mutants of Arabidopsis are susceptible to the soil fungus Pythium irregulare. Plant J. 15:747-754.

Thomma, B. P. H. J., Eggermont, K., Penninckx, I. A. M. A., MauchMani, B., Vogelsang, R., Cammue, B. P. A., and Broekaert, W. F. 1998 Separate jasmonate-dependent and salicylate-dependent defense-response pathways in Arabidopsis are essential for resistance to distinct microbial pathogens. Proc. Natl. Acad. Sci. U.S.A. 95:15107-15111.

Thomma, B. P. H. J., Eggermont, K., Tierens, F. M.-J., and Broekaert, W. F. 1999a. Requirement of functional ethylene-insensitive 3 gene for efficient resistance of Arabidopsis to infection by Botrytis cinerea. Plant Physiol. 121:1093-1101.

Thomma, B. P. H. J., Nelissen, I., Eggermont, K., and Broekaert, W. F. 1999b. Deficiency in phytoalexin production causes enhanced susceptibility of Arabidopsis thaliana to the fungus Alternaria brassicicola. Plant J. 19:163-171.

Ton, J., Pieterse, C. M. J., and Van Loon, L. C. 1999. Identification of a locus in Arabidopsis controlling both the expression of rhizobacteriamediated induced systemic resistance (ISR) and basal resistance against Pseudomonas syringae pv. tomato. Mol. Plant-Microbe Interact. 12:911-918.

Uknes, S., Mauch-Mani, B., Moyer, M., Potter, S., Williams, S., Dincher, S., Chandler, D., Slusarenko, A., Ward, E., and Ryals, J. 1992. Acquired resistance in Arabidopsis. Plant Cell 4:645-656.

Uknes, S., Winter, A. M., Delaney, T., Vernooij, B., Morse, A., Friedrich, L., Nye, G., Potter, S., Ward, E., and Ryals, J. 1993. Biological induc- 
tion of systemic acquired resistance in Arabidopsis. Mol. PlantMicrobe Interact. 6:692-698.

Van Loon, L. C. 1997. Induced resistance in plants and the role of pathogenesis-related proteins. Eur. J. Plant Pathol. 103:753-765.

Van Loon, L. C., Bakker, P. A. H. M., and Pieterse, C. M. J. 1998. Systemic resistance induced by rhizosphere bacteria. Annu. Rev. Phytopathol. 36:453-485.

Van Wees, S. C. M., Pieterse, C. M. J., Trijssenaar, A., Van 't Westende, Y. A. M., Hartog, F., and Van Loon, L. C. 1997. Differential induction of systemic resistance in Arabidopsis by biocontrol bacteria. Mol. Plant-Microbe Interact. 10:716-724.

Van Wees, S. C. M., Luijendijk, M., Smoorenburg, I., Van Loon, L. C., and Pieterse, C. M. J. 1999. Rhizobacteria-mediated induced systemic resistance (ISR) in Arabidopsis is not associated with a direct effect on known defense-genes but stimulates the expression of the jasmonateinducible gene Atvsp upon challenge. Plant Mol. Biol. 41:537-549.

Van Wees, S. C. M., De Swart, E. A. M., Van Pelt, J. A., Van Loon, L. C., and Pieterse, C. M. J. 2000. Enhancement of induced disease resistance by simultaneous activation of salicylate- and jasmonate-dependent defense pathways in Arabidopsis thaliana. Proc. Natl. Acad. Sci. U.S.A. 97:8711-8716.

Vernooij, B., Friedrich, L., Ahl Goy, P., Staub, T., Kessmann, H., and Ryals, J. 1995. 2,6-Dichloroisonicotinic acid-induced resistance to pathogens without the accumulation of salicylic acid. Mol. PlantMicrobe Interact. 8:228-234

Vijayan, P., Shockey, J., Lévesque, C. A., Cook, R. J., and Browse, J. 1998. A role for jasmonate in pathogen defense of Arabidopsis. Proc. Natl. Acad. Sci. U.S.A. 95:7209-7214. 